\title{
Sensitivity and offset changes of a fast-response open-path infrared gas analyzer during long-term observations in an Arctic environment
}

\author{
Hiroki IWATA*, ${ }^{\dagger}$, Yoshinobu HARAZONO*, **, and Masahito UEYAMA** \\ $\left(\begin{array}{c}* \text { International Arctic Research Center, University of Alaska Fairbanks, } \\ 930 \text { Koyukuk Drive, Fairbanks, Alaska, 99775-7340, USA } \\ * * \text { Graduate School of Life and Environmental Sciences, Osaka Prefecture } \\ \text { University, 1-1 Gakuen-cho, Sakai, Osaka, 599-8531, Japan }\end{array}\right)$
}

\begin{abstract}
We examined sensitivity and offset changes of a fast-response open-path gas analyzer in an Arctic environment. Output voltage from the gas analyzer was compared to water vapor density calculated from a slow-response thermometer and hygrometer, and then sensitivity and offset were determined. This procedure serves as an effective calibration of the gas analyzer. In this study, changes in sensitivity caused over- or underestimation of up to $10 \%$ in water vapor flux. An effective strategy was established for calibrating a gas analyzer in the field in the Arctic environment. The strategy comprises the following main points: 1) Parallel observation with a stable slow-response sensor is needed to calibrate a fast-response gas analyzer. The slow-response sensor should be calibrated as necessary. 2) The appropriate period length for applying the effective calibration should be determined, considering the data availability, the stability of sensors used, and the local environment, to obtain a statistically robust sensitivity and offset. 3) Rain events may cause a step change in offset, but not in sensitivity. Periods for applying effective calibration should be carefully determined in order to account for possible step changes in the sensitivity and offset. Additionally, this methodology may be applied to other environments in principle.
\end{abstract}

Key words: Air temperature, Calibration, Latent heat flux, LI-7500, Water vapor.

\section{Introduction}

For understanding the responses of terrestrial ecosystems to climate change, observations of surface fluxes of water vapor, carbon dioxide $\left(\mathrm{CO}_{2}\right)$, and energy provide useful information. Currently, more than 400 sites are used for these flux observations throughout the world, over a wide range of climates and ecosystems, on a long-term basis (Baldocchi, 2008).

During these observations, infrared gas analyzers are widely used for measuring turbulent fluctuations of water vapor and $\mathrm{CO}_{2}$. These data are combined with wind velocity data to calculate surface fluxes, using the eddy covariance technique (Kaimal and Finnigan,

Received; December 27, 2011.

Accepted; May 14, 2012.

†Corresponding Author: hiwata@alaska.edu
1994). For this application, analyzers should have a fast response to turbulent fluctuations in water vapor and $\mathrm{CO}_{2}$ - commonly up to $10 \mathrm{~Hz}$ - and should also be stable over the time during which fluxes are calculated-typically half an hour (Monji, 2003). Due to recent technological developments, these analyzers have attained the necessary performance for this eddy covariance observation. However, though the analyzers are sufficiently stable for the eddy covariance application at each averaging period, this does not mean calibration for long-term observation is unnecessary. In reality, the change in sensitivity and offset over longer periods (e.g., months) is inevitable (e.g., SerranoOrtiz et al., 2008). Periodical calibrations using a standard gas are recommended by the manufacturer. Change in sensitivity directly affects the magnitude of fluxes, and so it is important to keep the analyzer calibrated for accurate evaluation of the atmosphere- 
ecosystem exchange of water and carbon on a longterm basis.

In some circumstances, though, such as at remote sites and sites in severe environments, it may be difficult to perform the calibration at regular intervals. In these cases, calibrating the gas analyzers in the field against a parallel observation from slow-response sensors (a procedure hereafter termed "effective calibration") may be useful. Most observations conduct parallel measurements of humidity and $\mathrm{CO}_{2}$ concentration using slow-response sensors. Slow-response sensors are usually more durable than fast-response sensors (Stull, 1988), and they can also be expected to be more stable. Thus, slow-response sensors need less frequent calibrations. Such properties suggest the usefulness of slow-response sensors for effective calibration of fast-response sensors.

In this article, we report on the variations in sensitivity and offset of a fast-response gas analyzer for water vapor density, and on the applicability of effective calibration of the gas analyzer using parallel measurement of a slow-response sensor in an Arctic environment. In an Arctic environment, air temperature ranges more than $60^{\circ} \mathrm{C}$ during the year; it is thus possible to examine the variations in sensitivity and offset of an analyzer over a wide range of air temperatures. Another objective of this study is to establish an efficient strategy for calibrating a fast-response gas analyzer for long-term observation in these Arctic environments.
Ecosystems in the Arctic region are gaining more attention as a result of attempts to clarify the region's response to climate change (e.g., Hinzman et al., 2005). Establishing such a strategy will contribute to accurate evaluation of the atmosphere-ecosystem exchange, leading to its establishment as a practical method in the Arctic, as well as in other ecosystems.

\section{Data and Analysis}

Data analyzed in this study were obtained in a black spruce forest in Fairbanks, Alaska $\left(64^{\circ} 52^{\prime} \mathrm{N}, 147^{\circ} 51^{\prime} \mathrm{W}\right.$, $155 \mathrm{~m}$ a.s.l.) from June 9, 2006 to June 15, 2008. The climate in Fairbanks is continental; mean lowest air temperature in January and mean highest in July are $-28^{\circ} \mathrm{C}$ and $23^{\circ} \mathrm{C}$, respectively. Mean annual precipitation is $263 \mathrm{~mm} \mathrm{yr}^{-1}$ (Shulski and Wendler, 2007). The extremely low air temperature is typical for the Arctic, and this site is ideal for examining the response of a fast-response gas analyzer to a wide range of air temperatures. Figure 1 shows seasonal variation of air temperature and water vapor density observed at this site over these two years.

An open-path gas analyzer (LI-7500; Li-Cor, USA) was installed at a height of $6 \mathrm{~m}$ for the eddy covariance observation, and the changes in calibration coefficients of this instrument for water vapor (i.e., sensitivity and offset) were examined. To calibrate the open-path gas analyzer, water vapor density was obtained from air temperature and relative humidity observed with plati-

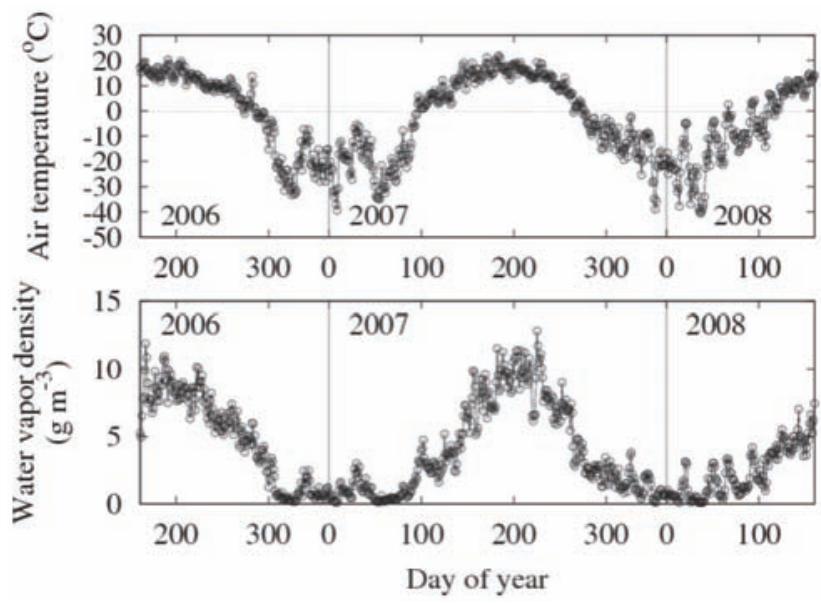

Fig. 1. Seasonal variation of daily mean air temperature and water vapor density, observed with a HMP45 at $8 \mathrm{~m}$ in the black spruce forest site. Data below $-40^{\circ} \mathrm{C}$ was filled using data from a thermocouple, since the measurement range of $\mathrm{HMP} 45$ is -40 to $60^{\circ} \mathrm{C}$. 


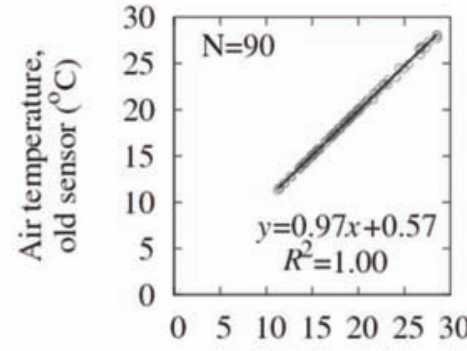

Air temperature, new sensor $\left({ }^{\circ} \mathrm{C}\right)$

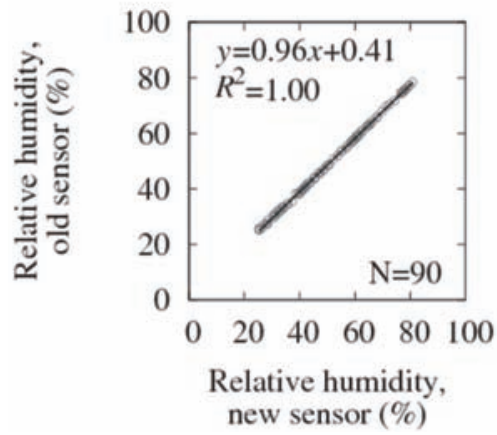

Fig. 2. Comparison of an old HMP45 sensor with a new HMP45 sensor. The old HMP45 sensor had been used at the same observation site for a year before this comparison.

num-resistant thermometers and capacitive hygrometers (HMP45; Vaisala, Finland). The HMP45 sensors were installed in a radiation-shielded double-tube and ventilated using an electric fan. According to the instruction manual, the HMP45 thermometer can measure temperature within $\pm 0.2-0.4^{\circ} \mathrm{C}$ error for the typical temperature range in Fairbanks. The accuracy of relative humidity measurements at $20^{\circ} \mathrm{C}$ is $\pm 2 \%$ and $\pm 3 \%$ for $0-90 \%$ and $90-100 \%$ ranges, respectively. We calculated a typical deviation due to measurement error in water vapor density for the summer time in Fairbanks at $\pm 300 \mathrm{mg} \mathrm{m}^{-3}$, which is about $3 \%$ of the absolute value. The HMP45 sensors were replaced with new sensors on June 22, 2007. The long-term stability of the HMP45 sensor was checked by comparing an old sensor with a new sensor. The comparison suggested that the change in sensitivity and offset of the hygrometer were $4 \%$ and $0.4 \%$, and those of the thermometer were $3 \%$ and $0.6^{\circ} \mathrm{C}$ over a year (Fig. 2). More details on the observations can be found in Ueyama et al. (2006) and Iwata et al. (2010).

The Goff-Gratch formula over water or ice (List,
1951) was used to calculate saturated water vapor pressure depending on temperature. Average values of 4 and $8 \mathrm{~m}$ were used to match with data from the openpath gas analyzer at $6 \mathrm{~m}$. A more sophisticated approach, such as estimating water vapor density at $6 \mathrm{~m}$ by fitting a curve to an observed profile of water vapor density, also has estimation error. In addition, the estimated values using this approach, when compared to simple average data from two heights, were not different by more than the observational error of HMP45. Hence, we adopted a simple averaging approach in this study.

Output of the LI-7500 analyzer was compared with water vapor density from the HMP45 for an arbitrary period length depending on analyses. The linear least square method was applied to obtain sensitivity and offset. The sensitivity and offset were defined as the slope and y-intercept of the regression equations, respectively. Outliers were removed before determination of sensitivity and offset. Changes in sensitivity and offset of the LI-7500 were then examined.

\section{Results and Discussion}

Figure 3 shows a typical comparison between water vapor density from the HMP45 and voltage output from the LI-7500 for a half-month period (from June 10 through June 24, 2006) as an example. The relationship was linear and the correlation was quite high, yielding a coefficient of determination, $R^{2}$, of 0.99 . The $R^{2}$ ranged from 0.94 to 0.99 for other periods of a similar length, showing that both signals from the sensors were highly consistent within the periods. Thus, it is possible to calibrate the LI-7500 with a parallel observation using a slow-response sensor.

An important consideration is over what length of period the sensitivity and offset should be determined, since a small amount of data leads to a large statistical uncertainty of coefficients, while a long period of data may be influenced by the drift of the gas analyzer. To determine an appropriate period length, we examined the variation in sensitivity and offset while increasing the length of period over which the sensitivity and offset were determined. Figure 4 is an example plot for a 30-day period, from June 10 through July 9, 2006. Both sensitivity and offset showed larger variations with increasing period length for one to six days. Both sensitivity and offset remained relatively stable for seven to fifteen days, and then gradually varied again 


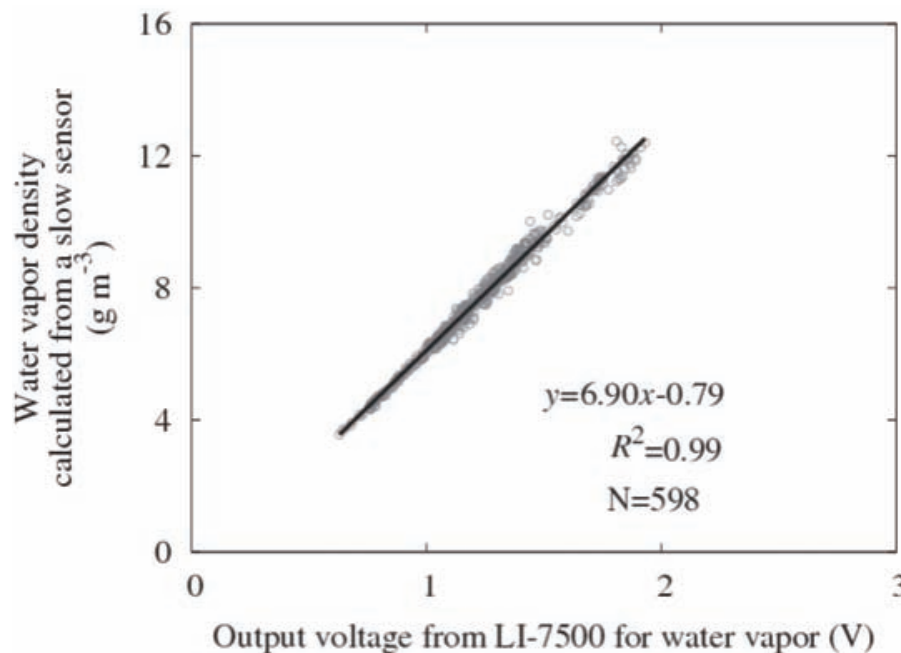

Fig. 3. Comparison between LI-7500 output voltage for water vapor and parallel observations of water vapor density from HMP45 for a half-month period from June 10 through June 24, 2006. Each measurement represents 30-min average.
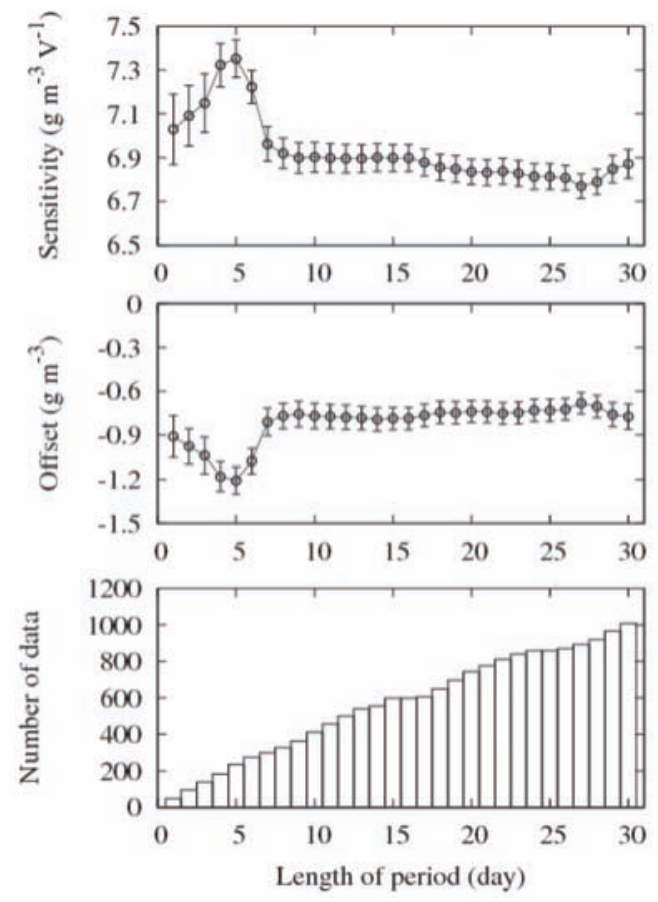

Fig. 4. Variations of sensitivity (upper panel) and offset (middle panel) with increasing length of period from which these coefficients were determined. The error bars indicate $95 \%$ confidence intervals. The lower panel shows the number of data for each length of period. with a further increase in length. The error bar indicates a $95 \%$ confidence interval, and this interval clearly decreased with increasing period length for the first five days for both sensitivity and offset. We examined these variations during other seasons and obtained qualitatively similar variations. The large variations in sensitivity and offset for the one- to six-day period are probably due to statistical uncertainty related to a limited amount of data. Water vapor density at $6 \mathrm{~m}$ was estimated from two heights nearby in this study, and the related error may vary depending on micrometeorological conditions, such as atmospheric stability. This error may amplify the variation of calibration coefficients for the one- to six-day period. When the sensitivity and offset were determined for each day, they showed large variations from day to day (data not shown). From this analysis, we selected half-month periods for determining the sensitivity and offset in order to examine the variations of sensitivity and offset in the long term, considering the tradeoff between the statistical robustness of the calibration coefficients and the effect from the drift of the gas analyzer.

Figure 5 shows the variations in sensitivity and offset over two years. Neither sensitivity nor offset remained constant. The sensitivity deviated from the original value of $7.20 \mathrm{~g} \mathrm{~m}^{-3} \mathrm{~V}^{-1}$, which was determined by factory calibration. The relative error ranged from $-11 \%$ to $14 \%$ from day of year 120 to 300 (Fig. 5, 

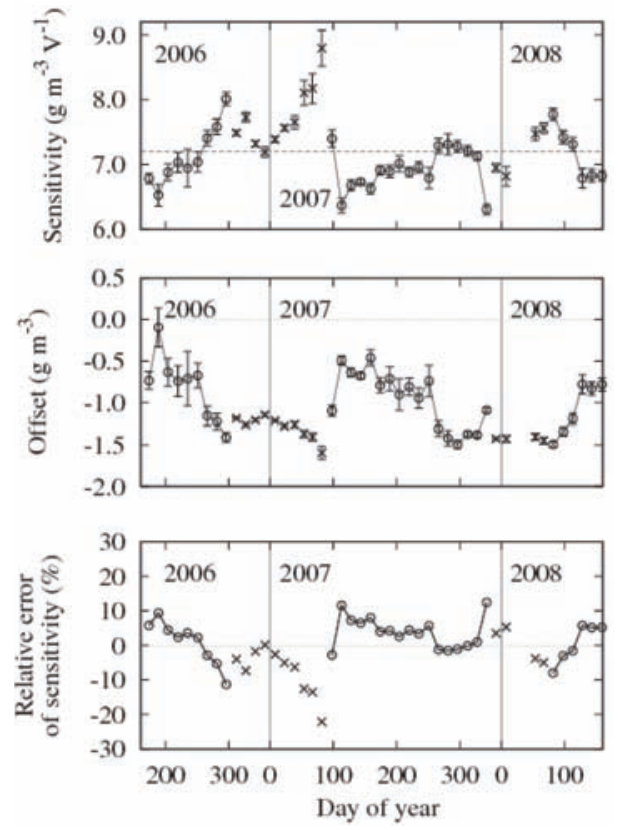

Fig. 5. Changes in sensitivity (upper), offset (middle), and relative error of sensitivity (bottom) over two years. Data including when air temperature was less than $-25^{\circ} \mathrm{C}$ are shown with crosses. The error bars indicate $95 \%$ confidence intervals. The dashed line in the upper graph indicates the sensitivity determined by factory calibration.

bottom), a span corresponding to the snow-free period. Cross symbols in Fig. 5 include data when air temperature was below $-25^{\circ} \mathrm{C}$. The LI-7500 used in this study was not verified for -25 to $-40^{\circ} \mathrm{C}$ by the manufacturer; however, the fact that a linear relationship with data from the HMP45 was held and correlation was high even below $-25^{\circ} \mathrm{C}$ (data not shown) suggests that the gas analyzer operated fairly well during extremely cold periods. Around day of year 80 in 2007, the sensitivity deviated largely, leading to underestimation of up to $22 \%$ for water vapor flux. The relationship between sensitivity and air temperature at $8 \mathrm{~m}$ when air temperature was higher than $-25^{\circ} \mathrm{C}$ was examined. There was a tendency for sensitivity to increase with decreasing temperature. Student t-test indicated, however, that the slopes of regression equations were not statistically different from zero ( $p=0.12$ and $p=0.37$ for 20062007 and 2007-008, respectively) .

Rainfall may be another influential factor in the changes in sensitivity and offset, since rainfall either washes out dust accumulated on the window of the LI7500 or, contrarily, soils the window, depending on the amount of dust contained in the raindrops (SerranoOrtiz et al., 2008). To investigate the influence of accumulated dust and rainfall, consecutive seven-day periods with little rain followed by rainfall were extracted; sensitivity and offset for the seven-day periods were then compared with those after the rainfall events (Figs. 6a, b). The differences in sensitivity and offset were not statistically significant (Table 1 ), and furthermore these changes were within the change in sensitivity and offset between corresponding half-monthly periods. Overall, no clear step change in sensitivity requiring special attention, beyond varying the sensitivity half-monthly, was observed after rain events throughout the observation period. A detectable shift of the regression line was observed after a heavy rain event during the day of year 186-188 period (Fig. 6c), although the difference was not statistically significant (Table 1). In addition, this change in offset does not affect covariance in the eddy flux calculation. SerranoOrtiz et al. (2008) also reported step changes in the absolute values of $\mathrm{CO}_{2}$ density and water vapor density in response to rain events and manual lens cleaning. They further noted that the contamination of the window affected only the offset and not the sensitivity.

Biases in calculated flux when neglecting sensitivity change are considerable (Fig. 5, bottom). When sensitivity changes were not considered, the magnitude of flux can be either underestimated or overestimated in direct proportion to the difference in sensitivity. In the case of our observations in 2007, annual accumulated evapotranspiration was overestimated by $6 \% \quad(9.5$ $\mathrm{mm})$.

Period lengths for employing effective calibration in this study were seven to fifteen days for the combination of the LI-7500 and HMP45 (Fig. 4). The minimum and maximum of appropriate period length are likely influenced by data availability and the stability of sensors to be used, respectively. For example, in rainy conditions, data from an open-path gas analyzer are often rejected. In this case, the minimum appropriate period length will increase. In addition, frequency of rain events and atmospheric turbidity may also influence the appropriate length of period by changing how much dust accumulates on the window of the open-path gas analyzer. Hence, it is recommended that 
Table 1. Changes to calibration coefficients after rain events in Fig. 6. Numbers in parentheses indicate $95 \%$ confidence intervals.

\begin{tabular}{lccccccc}
\hline & \multicolumn{3}{c}{ Before the rain } & & \multicolumn{3}{c}{ After the rain } \\
\cline { 2 - 3 } \cline { 6 - 7 } & Sensitivity & Offset & $\mathrm{N}$ & Sensitivity & Offset & $\mathrm{N}$ \\
\hline Fig. 6a & $7.01( \pm 0.07)$ & $-0.86( \pm 0.08)$ & 311 & $6.91( \pm 0.11)$ & $-0.88( \pm 0.14)$ & 269 \\
\hline Fig. 6b & $6.97( \pm 0.15)$ & $-0.77( \pm 0.19)$ & 294 & $7.09( \pm 0.17)$ & $-0.80( \pm 0.20)$ & 173 \\
\hline Fig. 6c & $6.66( \pm 0.15)$ & $-0.67( \pm 0.22)$ & 167 & $6.78( \pm 0.14)$ & $-0.29( \pm 0.20)$ & 294 \\
\hline
\end{tabular}

appropriate period length for applying effective calibration should be determined considering the data availability, the stability of the sensors, and the local environment.

An advantage of effective calibration is that the accuracy of flux calculation is assured without laborious periodical calibrations using a standard gas. In addition, the calibration coefficients can be determined at desired intervals. This data-dependent procedure may make it possible to properly determine calibration coefficients in case there is a sudden change in sensitivity.

When manually calibrating an open-path gas analyzer for water vapor density, the use of a dew point generator, such as a Li-Cor LI-610, is often recommended (Li-Cor, Inc., 2001) . However, it is extremely difficult or practically impossible to perform a precise manual calibration in the field in an extremely cold environment or a remote site. In such environments, effective calibration may be applied to ensure the accuracy of observation in an economical manner. Effective calibration can be basically applied in any environment, although this study has focused on examining its applicability in the Arctic. It is also useful for a wellmaintained site, since it can work as reconfirmation for whether manual calibration has been performed correctly.

Although this manuscript has focused on the effective calibration of an open-path gas analyzer for water vapor, the same methodology can, in principle, be applied to $\mathrm{CO}_{2}$ as well, provided that a parallel observation with a stable or well-calibrated $\mathrm{CO}_{2}$ sensor is available.

The authors feel that there is intuitive thought among researchers that the change in sensitivity of fast-response gas analyzers can be quite small, even though a change in offset is substantial. However, this
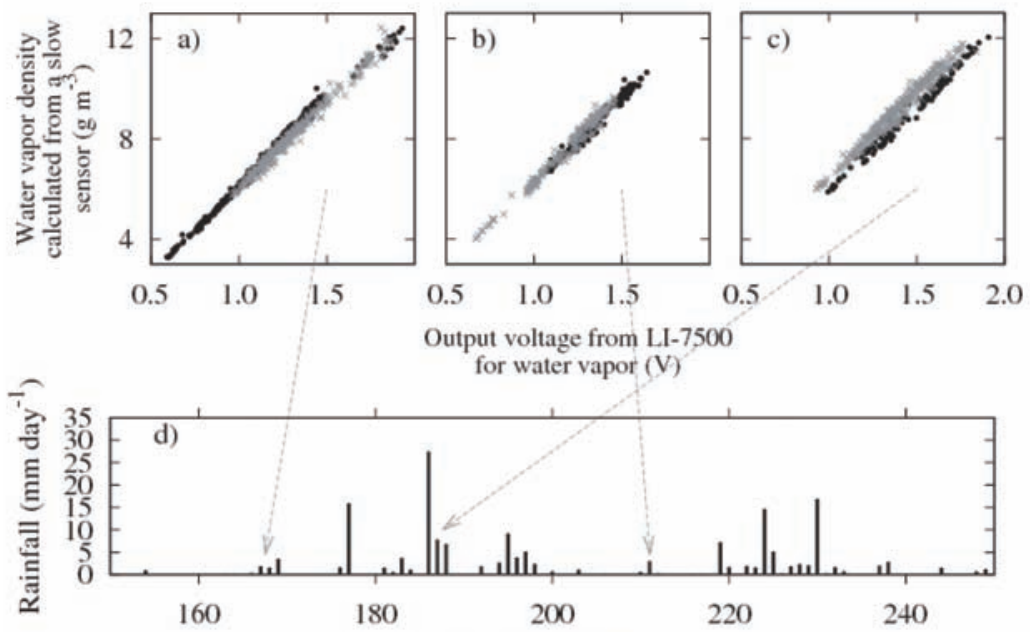

Output voltage from LI-7500

for water vapor $(\mathrm{V})$

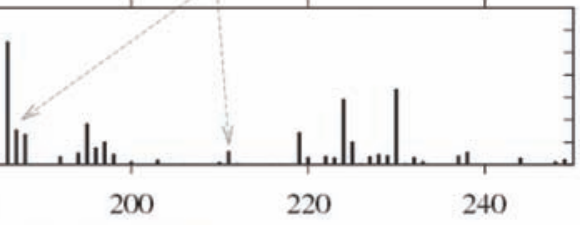

Day of year in 2006

Fig. 6. Changes to calibration equations after rain events (a, b, and c) along with time series of daily rainfall (d). Black circles and grey crosses correspond to data before and after rain, respectively. The calibration equations are shown in Table 1. 
research revealed that the range of sensitivity change was approximately $\pm 10 \%$ when a fast-response gas analyzer is used in an Arctic environment, and fastresponse gas analyzers should be calibrated as described in this manuscript and/or manually as necessary, in order to assure the accuracy of fluxes.

\section{Conclusions}

Effective calibration of open-path gas analyzers using a parallel measurement with a slow-response sensor is useful for flux observations in Arctic environments. This research revealed that the range of sensitivity change was approximately $\pm 10 \%$ when a fastresponse gas analyzer is used in an Arctic environment. For an efficient application of effective calibration in the Arctic environment, the following methodology is recommended: 1) Parallel observation with a stable slow-response sensor is needed for the application of effective calibration to a fast-response gas analyzer. The slow-response sensor should be calibrated as necessary. 2) The appropriate period length for applying the effective calibration should be determined considering the data availability, the stability of sensors used, and the local environment, in order to obtain statistically a robust sensitivity and offset. 3) Rain events may cause a step change in offset but not in sensitivity. Periods for applying effective calibration should be carefully determined to account for possible step changes in calibration coefficients.

\section{Acknowledgements}

This study was partly supported by the Carbon Cycle Program of IARC/NSF, the U.S. National Science Foundation, and IJIS (IARC/JAXA Information Systems). We would like to thank Nate Bauer for editing the manuscript and Chie Iwama for helping with field work. We are also grateful to the editor and two anonymous reviewers for the constructive comments.

\section{References}

Baldocchi, D., 2008: 'Breathing' of the terrestrial biosphere: lessons learned from a global network of carbon dioxide flux measurement systems. Aust. $J$. Bot., 56, 1-26.
Hinzman, L. D., Bettez, N. D., Bolton, W. R., Chapin, F. S., Dyurgerov, M. B., Fastie, C. L., Griffith, B., Hollister, R. D., Hope, A., Huntington, H. P., Jensen, A. M., Jia, G. J., Jorgenson, T., Kane, D. L., Klein, D. R., Kofinas, G., Lynch, A. H., Lloyd, A. H., McGuire, A. D., Nelson, F. E., Oechel, W. C., Osterkamp, T. E., Racine, C. H., Romanovsky, V. E., Stone, R. S., Stow, D. A., Sturm, M., Tweedie, C. E., Vourlitis, G. L., Walker, M. D., Walker, D. A., Webber, P. J., Welker, J. M., Winker, K. S., and Yoshikawa, K., 2005: Evidence and implications of recent climate change in northern Alaska and other Arctic regions. Clim. Change, 72, 251-298.

Iwata, H., Harazono, Y., and Ueyama, M., 2010: Influence of source/sink distributions on flux-gradient relationships in the roughness sublayer over an open forest canopy under unstable conditions. BoundaryLayer Meteorol., 136, 391-405.

Kaimal, J. C., and Finnigan, J. J., 1994: Atmospheric Boundary Layer Flows. Oxford University Press, Oxford, pp. 3-31.

Li-Cor, Inc., 2001: Open Path $\mathrm{CO}_{2} / \mathrm{H}_{2} \mathrm{O}$ Analyzer Instruction Manual. Nebraska, 155 pp.

List, R. J., 1951: Smithsonian Meteorological Tables (Sixth revised edition). Smithsonian Institution, Washington, $527 \mathrm{pp}$.

Monji, N., 2003: Plants and Micrometeorology-Turbulence and Fluxes in Plant Atmosphere-. Osaka Municipal Universities Press, Osaka, pp. 85124 (in Japanese).

Serrano-Ortiz, P., Kowalski, A. S., Domingo, F., Ruiz, B., and Alados-Arboledas, L., 2008: Consequences of uncertainties in $\mathrm{CO}_{2}$ density for estimating net ecosystem $\mathrm{CO}_{2}$ exchange by open-path eddy covariance. Boundary-Layer Meteorol., 126, 209-218.

Shulski, M., and Wendler, G., 2007: The Climate of Alaska. University of Alaska Press, Fairbanks, 216 pp.

Stull, R. B., 1988: An Introduction to Boundary Layer Meteorology. Kluwer Academic Publishers, Dordrecht, pp. 405-440.

Ueyama, M., Harazono, Y., Ohtaki, E., and Miyata, A., 2006: Controlling factors on the interannual $\mathrm{CO}_{2}$ budget at a subarctic black spruce forest in interior Alaska. Tellus, 58B, 491-501. 